\title{
WIND TUNNEL STUDY OF SAND TRANSPORT ON SURFACES COMPOSED OF BI-MODAL GRAIN-SIZE DISTRIBUTION
}

\author{
Souich Harikai ${ }^{1}$, Susumu Kubota ${ }^{2}$ and Shintaro Hotta ${ }^{3}$
}

\begin{abstract}
The transports rates and the threshold shear velocity on a sandy bed that grain sizes were bi-modally distributed were experimented in a large wind tunnel. The results showed that the transport rate followed a power law and the power was 2.5, and that the threshold shear velocities were the same or somewhat larger than those of the large diameter sand in the mixture.
\end{abstract}

Keywords: sand transport rate by wind; wind tunnel; bi-modal distribution

\section{INTRODUCTION}

The grain-size distribution on sandy beaches is typically well sorted due to the sorting action of currents and waves. However, the distribution of sand grain size on beaches which have more than one source of sand contributing to the littoral drift often attains complex characteristics. There is limited knowledge about wind-blown transport on sand surfaces with a complex grain-size distribution. Thus, as a first step towards filling this knowledge gap, experiments concerning the transport rate on a sandy bed composed of grain sizes that were bi-modally distributed were carried out in a wind tunnel. The purpose of this paper is to report on the experimental results and the associated analysis results.

\section{EXPERIMENTAL FACILITY AND PROCEDURE}

\section{Facility}

Wind tunnel. The experiments were carried out using a blow-off type wind tunnel with a test section that was $1.1 \mathrm{~m}$ high, $1.0 \mathrm{~m}$ wide, and $20 \mathrm{~m}$ long. A sand layer with a thickness of $10 \mathrm{~cm}$ was placed on the bottom of the tunnel implying a cross-section of $1.0 \mathrm{~m} \times 1.0 \mathrm{~m}$.

Sands studied. Sand taken from a natural beach was used in the experiment. The sand was sieved into four size classes encompassing the ranges $0.105-0.21 \mathrm{~mm}, 0.21-0.30 \mathrm{~mm}, 0.45-0.60 \mathrm{~mm}$, and $0.60-0.75 \mathrm{~mm}$, with the median diameters of $0.15 \mathrm{~mm}, 0.25 \mathrm{~mm}, 0.52 \mathrm{~mm}$ and $0.68 \mathrm{~mm}$, respectively (hereafter these sands are referred to as D15, D25, D52, and D68, respectively). Figure 1(a) shows the grain size cumulative distribution curves for the four sand sizes studied. Subsequently two types of sands, D15 and D52, and D25 and D68 were mixed with equivalent weight to form two types of mixed sand (these mixed sands are denoted as M(15-52) and M(25-68 ) ).

Other data sets including $\mathrm{M}(15-48)$ and $\mathrm{M}(30-100)$ that were obtained in different experiments are also analyzed here. The grain-size cumulative distribution curves for the four sand sizes utilized in these experiments are shown in Fig. 1(b).

Data set M(15-48) from the experiments was employed to evaluate the vertical distribution of sand transport rate (Hotta et al. 2006), whereas data set $\mathrm{M}(30-100)$ was obtained in a preliminary experiment to the present study. The sand, D30, with a color of light gray was taken from a natural beach and it was not sieved. The sand, D100, with a color of brown was filter sand for water supply. This sand was sieved well and washed with clean fresh water. Both sands, D30 and D100, were clearly distinguishable and easily separated by a sieve with a $0.6 \mathrm{~mm}$ opening

Wind speed measurement instrument. The vertical distribution of the wind speed was measured with a hot-film anemometer array consisting of fifteen anemometers. The elevations of the measurement points were approximately 2.5, 5.0, 7.5, 10.0, 12.5, 15.0, 17.5, 20.0, 22.5, 25.0, 27.5, 30.0, 40.0, 50.0, and $60.0 \mathrm{~cm}$ above the sand surface.

\section{Procedure}

Procedure for measuring transport rate. The sand was spread over the test section in the 20-m long tunnel and the sand surface was flattened, after which the wind was generated. The time period for blowing the wind over the bed varied from two minutes to ten minutes, depending on the wind speed employed. After the wind stopped blowing, the sand volume which passed the downstream end

\footnotetext{
${ }^{1}$ Coastal Eng. Consultants Co., Ltd., Tukudo-hachiman 2-21, Shinjuku-ku, Tokyo, 162-0815, Japan

${ }^{2}$ Dept. of Civil Eng., Nihon Univ., Kanda-surugadai 1-8-14, Chiyoda-ku, Tokyo, 101-8308, Japan

${ }^{3}$ Kokubun 2-8-16, Ichikawa, Chiba Pref., 272-0834, Japan
} 
of the test section was collected and weighed. For the mixed sand the weighed sand was sieved to separate the original two sand classes and the separated sands were weighed.

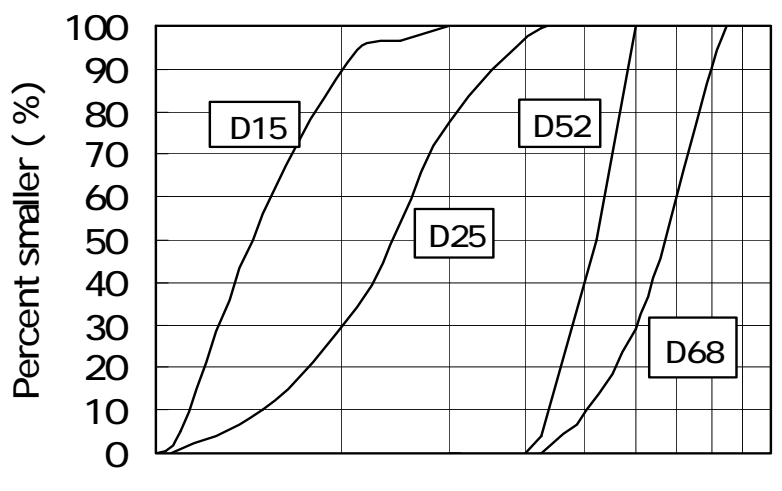

0.1 1 Grain size ( $\mathrm{mm}$ )

(a) M (15-52) and M (25-68).

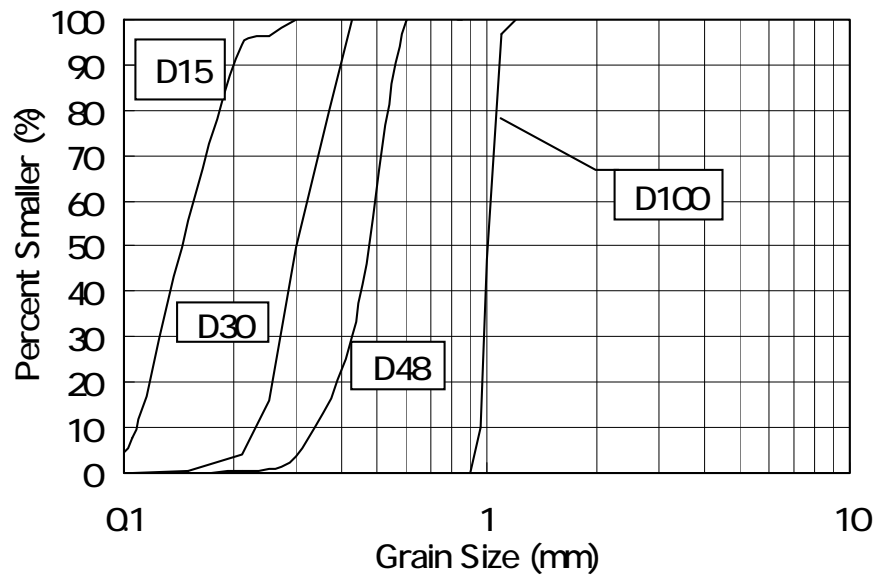

(b) $M(15-48)$ and $M(30-100)$.

Figure 1. Grain-size cumulative distribution curves.

Each experimental run was carried out twice. A third run was performed when the difference in the transport rate between the two runs was greater than $3 \%$. The average value of the most reliable two runs was employed for further analysis.

For four series of the experiments an effort was made to blow the same fixed wind speeds while keeping the rotational frequency of the fan constant. The fundamental rotational frequencies applied were $270,410,550,690,830$, and $970 \mathrm{rpm}$, although other frequencies were employed as well when there was a need for it.

Four series of experiments for D68, M(25-68), D52, and M(15-52) were carried out. Experiments for D15 and D25 were not conducted because data already existed for these sands from previous experimental studies (Hotta et al. 2004).

Procedure for determining threshold condition. The wind was applied after the sand surface was flattened. At first the wind speed in the center of the tunnel (at an elevation of $50 \mathrm{~cm}$ above the sand surface) was kept around $3.0 \mathrm{~m} / \mathrm{s}$. Then the wind speed was increased with about $0.3 \mathrm{~m} / \mathrm{s}$ (corresponding to about $15 \mathrm{rpm}$ ) and the floor of the sand collecting chamber located at the end of tunnel was carefully observed during three minutes. The wind speed was increased further if no sand was transported. The same procedure was repeated and it was estimated that the sand began to move when grains were continuously falling on the floor of the collecting chamber. This process was repeated three times. The sands accumulated on the floor of the collecting chamber were limited to the small-diameter sand in the mixtures when the threshold conditions were exceeded. 


\section{RESULTS AND DISCUSSION}

As mentioned before, the average values of the most reliable two runs in the transport rate experiments and three runs in the threshold experiments were employed in the following analysis.

\section{Vertical distribution of wind speed}

Figure 2 shows a semi-logarithmic plot of the vertical distribution of the wind speed on the D52, D68, $M(15-52)$, and $M(25-68)$ sand surfaces. From Fig. 2 it is clear that the distribution obeys the logarithmic law below an elevation of about $30 \mathrm{~cm}$ and that the wind speed is approximately constant in the upper region above $30 \mathrm{~cm}$, although some scatter exists in the data. Careful inspection of Fig. 2 shows that the elevation to which the logarithmic law is valid increases with increasing wind speed.
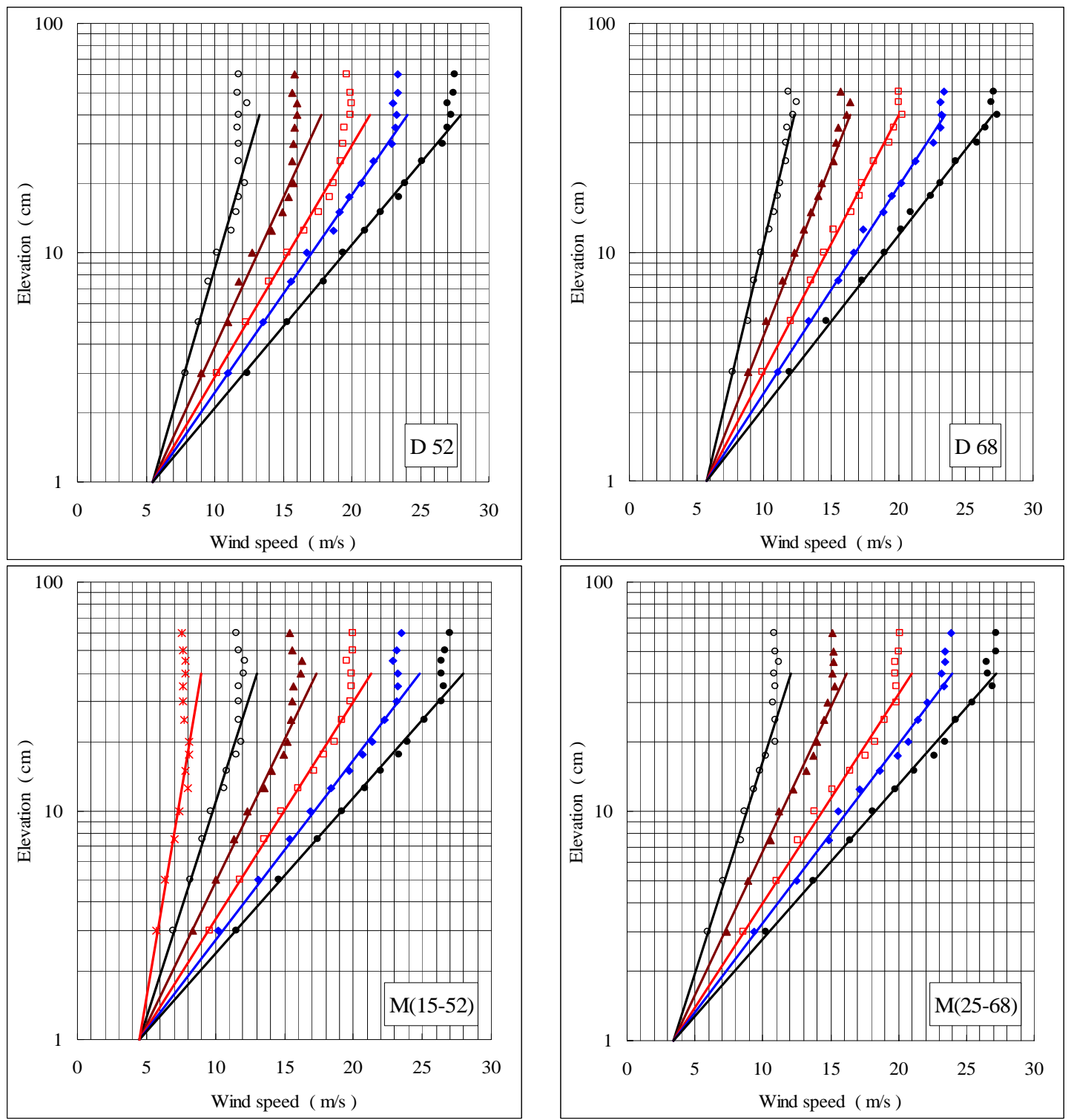

Figure 2. Vertical distribution of the wind speed. 
The logarithmic law on the moving sand surface is expressed as

$$
u_{z}=5.75 u_{*} \log { }_{10} \frac{z}{z^{\prime}}+u^{\prime}
$$

where $u_{z}$ is the wind speed at an elevation $z, u_{*}$ is the shear velocity and $\left(u^{\prime}, z^{\prime}\right)$ is the focal point (Bagnold 1936,1973). The shear velocity was calculated from the data below $30 \mathrm{~cm}$ by means of the least-squares method. The focal point values $\left(u^{\prime}, z^{\prime}\right)$ obtained from Fig. 2 are $(460 \mathrm{~cm} / \mathrm{s}, 0.9 \mathrm{~cm})$ for D52, $(550 \mathrm{~cm} / \mathrm{s}, 1.0 \mathrm{~cm})$ for M(15-52), $(570$ ' cm/s, $1.0 \mathrm{~cm})$ for D68, and $(480 \mathrm{~cm} / \mathrm{s}, 1.0 \mathrm{~cm})$ for M(25$68)$. It is difficult to detect any specific tendencies in the determined values.

\section{The threshold shear velocity}

The threshold shear velocity $u_{*_{c}}$ at which the sand grains begin to move is given by,

$$
u_{* c}=A \sqrt{\frac{\rho_{s}-\rho_{a}}{\rho_{a}} g d}
$$

where $\rho_{s}$ and $\rho_{a}$ are the densities of sand and air, respectively, $g$ is the acceleration due to gravity, $d$ is the sand grain diameter, and $A$ is an empirical coefficient with a value of about 0.1 (Bagnold 1973). The threshold shear velocities determined from the experiments and the values calculated using Eq. (2) are summarized in Table 1.

Values for the mixed sand surface determined from the experiments are the same or somewhat larger than those of the larger diameter sand in the mixture. The mixed sand surface increased the resistance to the wind, although the sands transported were limited to the small-size grains at conditions judged to be close to the threshold. This result is probably caused by large grains protecting small grains between them, and small grains that were between large grains firmly fixed the large grains and made it harder for the large grains to move.

\begin{tabular}{|c|c|c|c|}
\hline \multicolumn{4}{|c|}{ Table 1. Threshold shear velocities. } \\
\hline $\begin{array}{c}\text { Type of } \\
\text { Sand }\end{array}$ & $\begin{array}{c}\text { Eq. (2) } \\
(\mathrm{m} / \mathrm{s})\end{array}$ & $\begin{array}{c}\text { Experiment } \\
(\mathrm{m} / \mathrm{s})\end{array}$ & $\begin{array}{c}\text { Ratio of } \\
\text { median diameter }\end{array}$ \\
\hline D15 & 0.18 & & \\
D52 & 0.33 & 0.35 & 3.4 \\
M(15-52) & 0.23 & 0.37 & \\
D25 & 0.38 & 0.40 & \\
D68 & 0.38 & 0.40 & 2.7 \\
M(25-68) & 0.25 & 0.5 & \\
D30 & 0.45 & 0.74 & 3.3 \\
D100 & & & \\
M(30-100) & & & \\
\hline
\end{tabular}




\section{Ratio of large grains and small grains transported}

Figure 3 shows a plot of the ratio between the transported large grain-size weight and the transported total sand weight versus the shear velocity. With an increase in the shear velocity the ratio of large grain-size sand becomes larger. The ratio is about 50 \% when the shear velocity reaches 2.2 $\mathrm{m} / \mathrm{s}$.

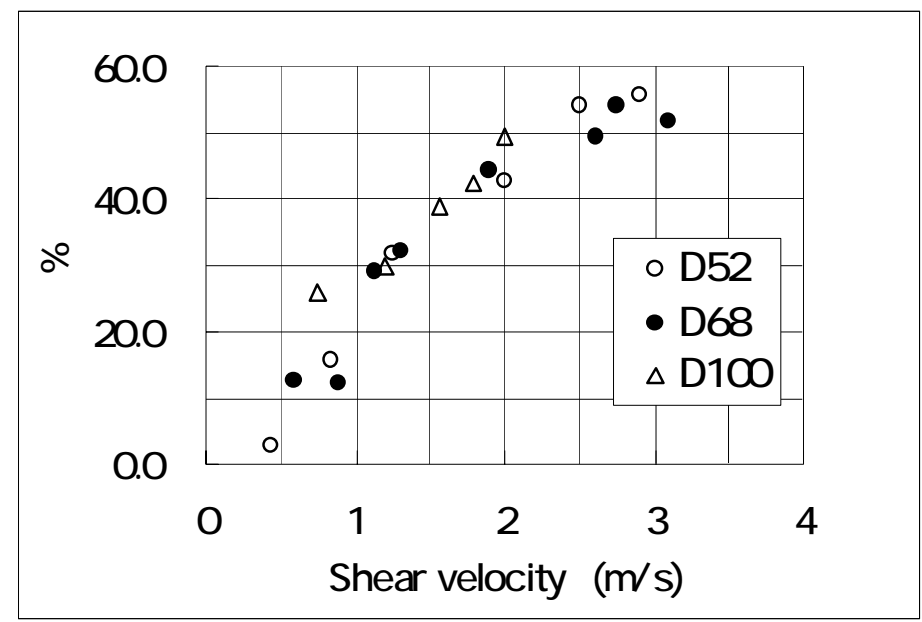

Figure 3. Ratio of large grains.

\section{Transport rate}

More than ten predictive sand transport rate formulas for wind-blown sand were presented( for example, Horikawa et al. 1986). Among those formulas is the simple power law due to Chepil (1945),

$$
Q=q\left(g / \rho_{a}\right)=C u^{3}
$$

where $Q$ is the apparent transport rate, $g$ is the acceleration due to gravity, $\rho_{a}$ is the density of air, $u *$ is the shear velocity, and $C$ is an experimental coefficient. Figure 4 shows a log-log plot of the transport rate versus the shear velocity for D52 and M(15-52) in (a), for D68 and M(25-68) in (b), for D48 and M(15-48) in (c), and for D100 and M(30-100) in (d). Viewing Fig. 4, it is possible to draw two straight lines through the data points indicating that the transport rate obeys a power law. The gradient of the straight lines drawn through the data for the sorted sands D and for the mixed sands M are 3.0 and 2.5, respectively. 

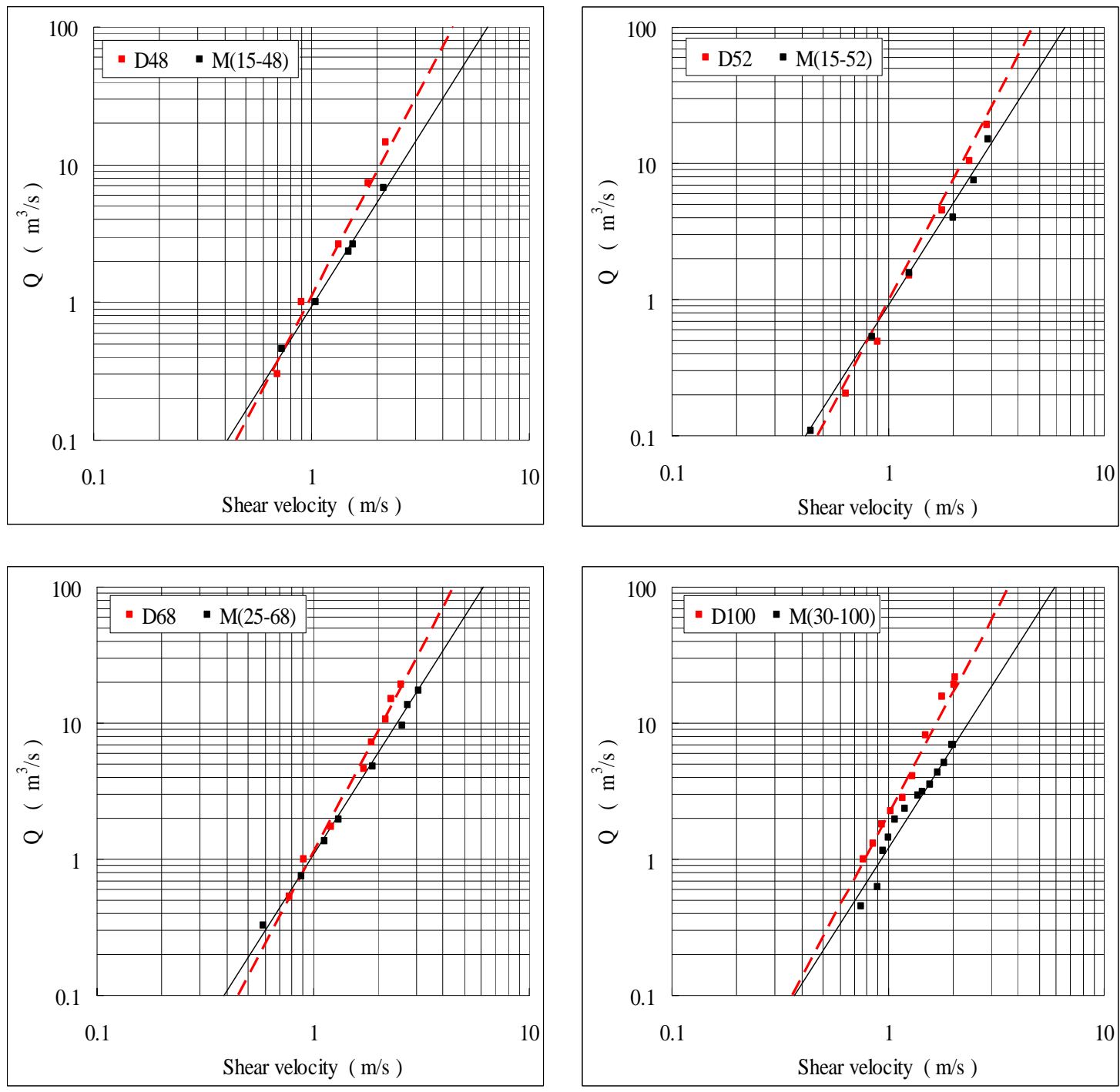

Figure 4. Sand transport rate.

The results shown in Fig. 4 can be described by Eq. (3), and the coefficient $C$ may be determined from the transport value at a shear velocity of $1.0 \mathrm{~m} / \mathrm{s}$ in Fig. 4.

Table 2 summarizes the values of the power $n$ and $C$ from the data determined by means of the least-squares method. It is possible to conclude that the power for D and $\mathrm{M}$ are 3.0 and 2.5, respectively.

\begin{tabular}{|c|c|c|c|}
\hline \multicolumn{4}{|c|}{ Table 2. Summary of coefficients $\boldsymbol{n}, \boldsymbol{C}$ and $\boldsymbol{B}$. } \\
\hline & $n$ & $\boldsymbol{C}$ & $\boldsymbol{B}$ \\
\hline D100 & 3.20 & 2.09 & 1.05 \\
D68 & 2.95 & 1.11 & 0.67 \\
D52 & 3.06 & 0.96 & 0.67 \\
D48 & 3.22 & 1.11 & 0.80 \\
D25 & 3.16 & 0.96 & 0.96 \\
D15 & 2.85 & 0.91 & 1.17 \\
M(30-100) & 2.60 & & \\
M(25-68) & 2.41 & 1.19 & 0.74 \\
M(15-52) & 2.51 & 0.89 & 0.78 \\
M(15-48) & 2.48 & 0.94 & 0.72 \\
\hline
\end{tabular}


Values of the coefficient $C$ are within a range of about 0.9 to 1.1 , except for D100, and no characteristic differences depending on the grain size was found.

Equation (3) does not contain any parameter that describes the influence of grain size. A typical predictive formula including the representative grain size as a parameter is the following equation due to Bagnold (1936, 1973),

$$
Q=q\left(g / \rho_{a}\right)=B(d / D s)^{1 / 2} u_{*}^{3}
$$

where $B$ is an experimental coefficient, $D s$ is the standard sand grain size taken as $0.25 \mathrm{~mm}$, and $\mathrm{d}$ is the representative grain size which is usually taken as the median diameter of the sand grain-size distribution.

By comparing Eqs. (3) and (4), the coefficients $C$ and $B$ can be related through:

$$
C=B(d / D s)^{1 / 2}
$$

Values of $B$ converted from $C$ are also listed in the Table 2. In converting for the mixed sand, the average sizes of the two sands were employed. Values of B range from 0.67 to 1.17 and no characteristic differences could be found with respect to the grain-size variation.

The values of B obtained by Bagnold were:

$1.5 \rightarrow$ for nearly uniform sand,

$1.8 \rightarrow$ for naturally graded sand, such as that found on dunes,

$2.8 \rightarrow$ for sand with a very wide range of grain size.

Concerning $B$, many values have been reported from wind tunnel experiments and field measurements. The values in the literature cover a wide range from about 0.6 to 3.0. Thus, considerable differences in the value of $B$ exist. However, there are some tendencies to be noted in the reported $B$ - values. For coarse sand with median diameters larger than $0.25 \mathrm{~mm}$, the values of $B$ become large when the median diameter becomes large. Also, values of $B$ become large when the sand grain-size distribution becomes wide, as seen in Bagnold and noted above, although certain exceptional values are reported. It appears that the variation in $B$ depends on factors such as the efficiency of the trap used, sand characteristics, condition of the sand surface, moisture condition of the sand bed, and the measuring instruments employed in the wind tunnel or in the field. Values of $B$ obtained in the present study are in the range of small values. At present it is not completely clear why these small values were recorded in the experiments. However, one possible reason for the small values of $B$ is that the experiments were carried out on a flat bed surface in a short time fragment. Another possibility to consider is that the shear velocities were overestimated because of incorrect adjustment of the hot-film anemometers. 


\section{CONCLUDING REMARKS}

The main conclusions to be drawn from the present experiments are:

1. the transport rate of the bi-modally distributed sand followed a power law and the power was 2.5 ,

2. the threshold shear velocity at which the sand grains begin to move are the same or somewhat larger than those of the large diameter sand in the mixture.

These results can be applied for controlling blown sand on beaches. The associated sand transport decreases, especially in the high shear velocity region (the region higher than about $1.0 \mathrm{~m} / \mathrm{s}$, see Fig. 4), if fine sand is added to beaches which are composed by coarse sand larger than $0.48 \mathrm{~mm}$ in median diameter.

To apply this method to natural beaches the important thing is to determine a suitable value on $B$ for the mixed sand. The variation in B with sand grain size and characteristic values for bi-modally distributed sands should be studied in detail. Further comprehensive and systematic experiments are needed to obtain such information.

\section{REFERENCES}

Bagnold, R. M. 1936. The movement of desert sand, Proc., Roy., Soc., London, A, 157, 596-620.

Bagnold, R. M. 1973. The physics of blown sand and desert dunes, Chapman \& Hall Ltd., London, 265pp.

Chepil, W. S. 1945. Dynamics of wind erosion 3. The transport capacity of the wind, Soil Science, Vol. 60, 475-480.

Horikawa, K., S. Hotta, and N. C. Kraus. 1986. Literature review of sand transport by wind on a dry sand surface, Coastal Engineering, 9, 503-526.

Hotta, S., S. Kubota, N. Nakamura, and K. Hosaka. 2006. Wind-tunnel study of vertical distribution of sand transport rate by wind, Proceedings of $30^{\text {th }}$ International Conference on Coastal Engineering, ASCE, 2604-2616.

Hotta, S., S. Kubota, and S. Harikai 2004. On wind-blown transport rate of fine sand, Proceedings of $29^{\text {th }}$ International Conference on Coastal Engineering, ASCE, 2914-2926. 